\title{
Are Controversial Issues in Cervical Total Disc Replacement Resolved or Unresolved?: A Review of Literature and Recent Updates
}

\author{
Chun-Kun Park ${ }^{1}$, Kyeong-Sik Ryu ${ }^{2}$ \\ ${ }^{I}$ Department of Neurosurgery, Good Doctor Teun Teun Hospital, Anyang, Korea \\ ${ }^{2}$ Department of Neurosurgery, Seoul St. Mary's Hospital, College of Medicine, The Catholic University of Korea, Seoul, Korea
}

Since the launch of cervical total disc replacement (CTDR) in the early 2000s, many clinical studies have reported better outcomes of CTDR compared to those of anterior cervical discectomy and fusion. However, CTDR is still a new and innovative procedure with limited indications for clinical application in spinal surgery, particularly, for young patients presenting with soft disc herniation with radiculopathy and/or myelopathy. In addition, some controversial issues related to the assessment of clinical outcomes of CTDR remain unresolved. These issues, including surgical outcomes, adjacent segment degeneration (ASD), heterotopic ossification (HO), wear debris and tissue reaction, and multilevel total disc replacement (TDR) and hybrid surgeries are a common concern of spine surgeons and need to be resolved. Among them, the effect of CTDR on patient outcomes and ASD is theoretically and clinically important; however, this issue remains disputable. Additionally, HO, wear debris, multilevel TDR, and hybrid surgery tend to favor CTDR in terms of their effects on outcomes, but the potential of these factors for jeopardizing patients' safety postoperatively and/or to exert harmful effects on surgical outcomes in longer-term follow-up cannot be ignored. Consequently, it is too early to determine the therapeutic efficacy and cost-effectiveness of CTDR and will require considerable time and studies to provide appropriate answers regarding the same. For these reasons, CTDR requires longer-term follow-up data.

Keywords: Cervical vertebrae; Intervertebral disc degeneration; Total disc replacement; Controversial issue; Prognosis

\section{Introduction}

Anterior cervical discectomy and fusion (ACDF) is a wellknown gold standard surgical procedure for treating degenerative cervical spine diseases. ACDF has become the most popular surgical procedure for disorders of cervical spine. However, there have been some critical issues related to the use of ACDF that remain unresolved. Symptomatic pseudarthrosis following fusion failure is a main cause of chronic postoperative neck pain and approximately
$15 \%$ of these cases require revision surgeries [1]. When an autograft is used, donor site complications including pain or infection can reduce clinical success rates. Moreover, numerous biomechanical and clinical studies have revealed the evidence of junctional degeneration adjacent to fused levels because of increased biomechanical stress [27]. More than 5 years after cervical fusion surgery, up to $50 \%$ of patients exhibited adjacent segments degeneration (ASD) on radiographic imaging with symptomatic ASD $[8,9]$.

Received May 18, 2017; Revised Jul 17, 2017; Accepted Aug 12, 2017

Corresponding author: Kyeong-Sik Ryu

Department of Neurosurgery, Seoul St. Mary's Hospital, College of Medicine, The Catholic University of Korea, 222 Banpo-daero, Seocho-gu, Seoul 06591, Korea

Tel: +82-2-2258-6127, Fax: +82-2-594-4248, E-mail: nsdoc35@catholic.ac.kr 
Currently, cervical total disc replacement (CTDR) using various implants is used as a substitute for cervical fusion surgery. The rationale for CTDR is to preserve segmental motion and maintain normal physiological spinal kinematics. Unlike fusion surgery, CTDR is not associated with fusion-related complications like pseudo-arthrosis or graft-related complications. The preservation of segmental motion might prevent or delay ASD process by reducing mechanical stress. Spine surgeons anxiously await the results of various clinical trials, which could solidify the still-theoretical benefits of CTDR. Till date, most of these trials suggest that results of CTDR are favorable compared with those of ACDF [10-18]. However, complete clinical adoption of CTDR requires the settling of a number of controversial issues. In this chapter, we briefly discuss the general concept of CTDR while reviewing several critical and controversial issues which need to be settled.

\section{Implants}

Artificial discs were developed for the lumbar spine; many efforts were made to develop clinically useful artificial discs. SB Charité III, which has been revised twice since 1987, is first popular implant. Since then, various other implants have been introduced and are currently in clinical use [19-22].

With the success of the lumbar prosthetic device, a new passion for development of a cervical arthroplasty device has emerged. In 1989, the department of medical engi-

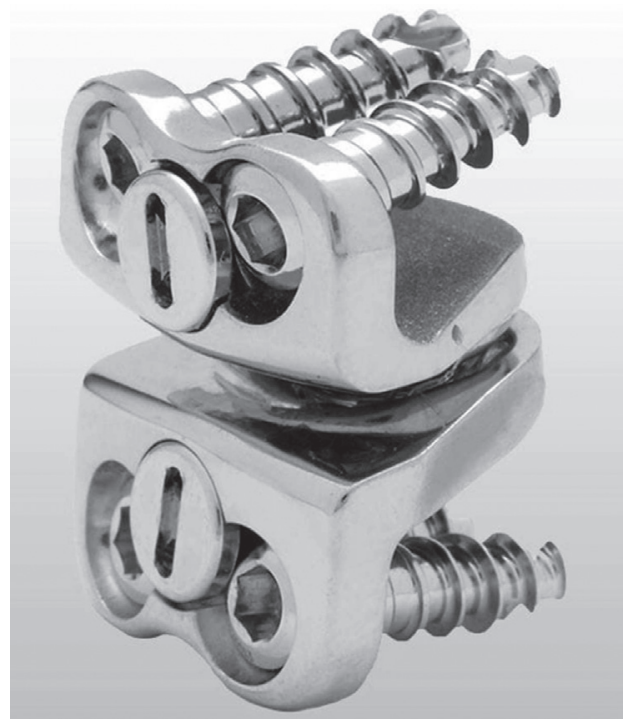

Fig. 1. Prestige artificial cervical disc. neering at Frenchay Hospital in Bristol, England initiated a project on artificial cervical joints [23]. The final product of this project was the Prestige disc comprising a twopiece steel plate that used a ball-in-socket configuration (Fig. 1). The lower plate was redesigned as a shallow ellipsoid saucer to increase the range of translation and rotation. The results of the 2-year pilot study with the Prestige disc in 15 patients revealed preserved segmental motion in 14 patients, and no device settling or migration [24]. Although there were no screw pull-outs, two incidents of screw breakage were noted.

A metal-on-plastic design called the Bryan disc was introduced in the late 1990s. The Bryan disc is a singlepiece unconstrained device with a completely variable instantaneous axis of rotation, comprising a polyurethane core that articulates between two titanium alloy shells (Fig. 2). It provides physiological coupled translation-flexionextension, and allows for shock absorption. Early research reports of the Bryan disc have demonstrated good results. In 2002, Goffin et al. [25] reported a study on a European prospective multicenter trial using the Bryan disc for treating single-level cervical disc disease. The clinical success rate was $86 \%$ in 60 patients at 6 months and $90 \%$ in 30 patients at 1 year, with motion preservation in all patients

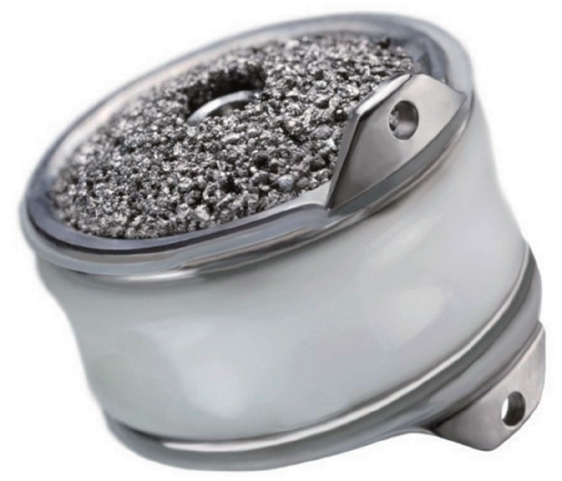

Fig. 2. Bryan artificial cervical disc.

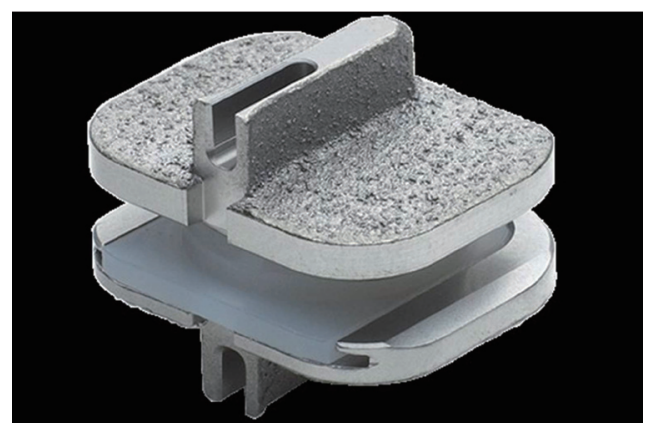

Fig. 3. ProDisc-C artificial cervical disc. 
and no evidence of device migration. Although many subsequent studies have reported good results over time, longterm follow-up results have exposed various problems. Postoperative segmental kyphosis is frequently reported, and is caused by segmental malalignment of the functional spinal unit and prosthetic shell angle of the Bryan prosthesis [26-29]. Prosthesis loosening, migration, and subsidence of the implant have been problematic $[30,31]$.

In 2002, the ProDisc-C implant was developed based on the same design principles as that of the ProDisc-L implant for the lumbar spine. The ProDisc-C is a metal polyethylene (PE) ball-in-socket design with two metal fins (Fig. 3). The unit comprises two cobalt-chrome endplates with an intervening polyurethane inlay. This semiconstrained device does not allow sagittal translation in order to prevent excessive motion. After a multicenter randomized prospective clinical trial, it was approved by the Food and Drug Administration (FDA) for use in the United States in December 2007 [32].

When cervical artificial discs were introduced in early 2000s, it was not easy for surgeons to assemble the devices and/or to insert the unforgiving prostheses. Nowadays, numerous cervical artificial discs have been introduced in the market, and CTDR has been popular worldwide for the surgical treatment of degenerative cervical spine diseases. Unlike early types of artificial discs, these new prostheses featured designs that were simple and easy to manage. Additionally, the devices themselves were more forgiving during surgical procedures, similar to cervical interbody cages. These changes in prosthesis design and procedure were driven by the continuous demand by surgeons coupled with industrial efforts to improve the implants.

\section{Surgical Techniques}

The surgical technique used to implant a cervical artificial disc is similar in approach and technique to conventional ACD, with or without fusion. The target vertebra is anteriorly accessed and the affected disc and all material compressing neural structures are removed. Osteophytes are removed to maximize the potential for normal range of motion (ROM) [33]. Whether the posterior longitudinal ligament (PLL) is divided or not remains controversial. One theory is that the removal of the PLL ensures complete decompression of the disc space and helps to restore intervertebral height [33]. Another theory is that preservation of the PLL, as long as it is undamaged, positively influences maintenance of ROM after CTDR [34].

Many biomechanical and clinical studies demonstrated that total uncinectomy (even unilateral), causes hypermobility of the segment and increases facet loads [35]. Thus, the hypertrophied uncinate processes should be removed. Once the uncinate processes are cleaned out bilaterally, the midline of the disc space can be determined. The center of the disc is defined as the midline of line between both sides of uncinate processes on the axial view, and between the anterior and posterior marginal line on the sagittal axis. This allows for accurate placement of the artificial disc in the center of the disc space. The endplates are prepared by removing the cartilaginous endplate and repositioning the surfaces until they are parallel to ensure even insertion of

Table 1. Indications and contraindications of cervical total disc replacement

$\begin{array}{ll}\text { Indications } & \text { Degenerative spine diseases involving C3 to T1 } \\ & \text { Radiculopathy/myelopathy failing conservative treatment } \\ & \text { Symptomatic multilevel diseases of more than three levels } \\ & \text { Adjacent level diseases after previous cervical fusion surgery } \\ & \text { Local/systemic infection } \\ & \text { Osteopenia/osteoporosis } \\ & \text { Instability (translation }>3 \text { mm difference or } 11 \text { degree of angular differences) } \\ & \text { Sensitivity or allergy to implant material } \\ & \text { Severe spondylosis (>50\% of disc height loss, bridging osteophyte, absence of motion, severe facet joint arthrosis) } \\ & \text { Ankylosing spondylitis } \\ \text { Contraindications } & \text { Rheumatoid arthritis } \\ & \text { Trauma } \\ & \text { Ossification of posterior longitudinal ligament } \\ & \text { Malignant conditions }\end{array}$


the prosthesis. Although the implantation techniques differ according to each artificial disc type, the basic principles remain similar. The size of the implant should be selected so that the endplate is able to completely fill up the empty space. A wider implant can prevent postoperative subsidence of the implant. The height of implant should be similar to normal disc height. The over-distraction of disc space and too tight positioning increases the load on facet joints and can cause postoperative neck pain or limited motion within the artificial disc. On the other hand, in case with too loose disc space or too low-height implant, foraminal stenosis and poor device function occurs. Final placement of the device is then confirmed using a fluoroscope.

North America Spine Society has proposed the guidelines for CTDR [36]. The indications and contraindications are listed in Table 1.

\section{Controversial Issues}

\section{Surgical outcomes}

There have been many clinical studies dealing with CTDR for treating degenerative cervical spine diseases. The summarized results of prospective clinical studies are listed in Table 2 [25,27,37-42]. Mummaneni et al. [37] presented the clinical results of a prospective, randomized comparison of ACDF versus CTDR, using the Prestige ST, with 3-5 years of follow-up. The study cohort included 347 patients who reached 3 years of follow-up and 111 who reached 5 years of follow-up. The Neck Disability Index (NDI) and visual analogue scale (VAS) scores were significantly better in the total disc replacement (TDR) group at 3 years that those of ACDF group ( $p=0.015$ and $p=0.044$, respectively), but were similar at 5 years $(p=0.214$ and $p=0.895$, respectively). There was no statistical difference between the groups for the 36-item short form (SF-36) physical component summary (PCS), SF-36 mental component summary, or VAS arm pain scores at 3 or 5 years. Latest follow-up evaluation revealed that the Prestige devices maintained a mean of 7.1 degrees of motion on flexion and extension X-rays. There were 7 TDR group removed versus $12 \mathrm{ACDF}$ removed. The TDR group maintained segmental motion up to 5 years after implantation.

Murrey et al. [38] reported the multicenter FDA investigational device exemption (IDE) study on the ProDisc-C TDR versus anterior discectomy and fusion for the treatment of one-level symptomatic cervical disc disease. A to- tal of 209 patients were enrolled in the study (ACDF, 106; TDR, 103). According to their results, both the groups experienced similar positive clinical outcomes; however, there was a statistically significant difference in the number of secondary surgeries with $8.5 \%$ of fusion patients requiring reoperation, revision, or supplemental fixation within the 24-month postoperative period, compared with $1.8 \%$ of TDR patients ( $p=0.033$ ). At 24 months, there was a statistically significant difference in the use of medication with $89.9 \%$ of TDR patients requiring no strong narcotics or muscle relaxants, compared with $81.5 \%$ of fusion patients. Thus, they concluded that TDR using the ProDisc-C is a safe and effective surgical treatment for patients with disabling cervical radiculopathy because of single-level disease. After evaluating primary and secondary measures, it was clear that clinical outcomes obtained after CTDR with ProDisc-C were either equivalent or superior to those obtained after fusion surgery.

Davis et al. [39] reported the results of a prospective randomized study evaluating the safety and efficacy of two-level TDR using a Mobi-C artificial disc compared with that of ACDF after a minimum 48 months of followup (TDR, 225 patients; ACDF, 105 patients). After 48 months, the follow-up rate was $89 \%$ in the TDR group and $81.2 \%$ in the ACDF group. They reported that both groups demonstrated significant clinical improvement, but the patients treated with CTDR showed greater improvement in NDI scores, 12-item short form (SF-12) PCS scores, patient satisfaction, and measures of overall success. The patients in the ACDF group underwent more reoperations at the index level (15.2\%; 16 of 105 patients, with a total of 18 reoperations) compared with patients who underwent TDR (4\%, 9 of 225 patients) $(p<0.001)$. Fusion failure was the most common cause of reoperations in the ACDF group.

Radcliff et al. [40] reported unique prospective randomized clinical study with 60 months follow-up in the 225 patients who received TDR using Mobi-C versus the 105 patients who underwent ACDF. Three independent authors critically reviewed the data and the methodology. They noted that patients who underwent TDR exhibited more improvement compared with those who underwent ACDF when considering the NDI, SF-12 PCS, and overall satisfaction. These authors also reported a higher reoperation rate in the ACDF group (16\%) than in the TDR group (4\%) ( $p=0.003$ ), without differences in the incidence of adverse events. ROM was preserved in the group with arthroplasty, 


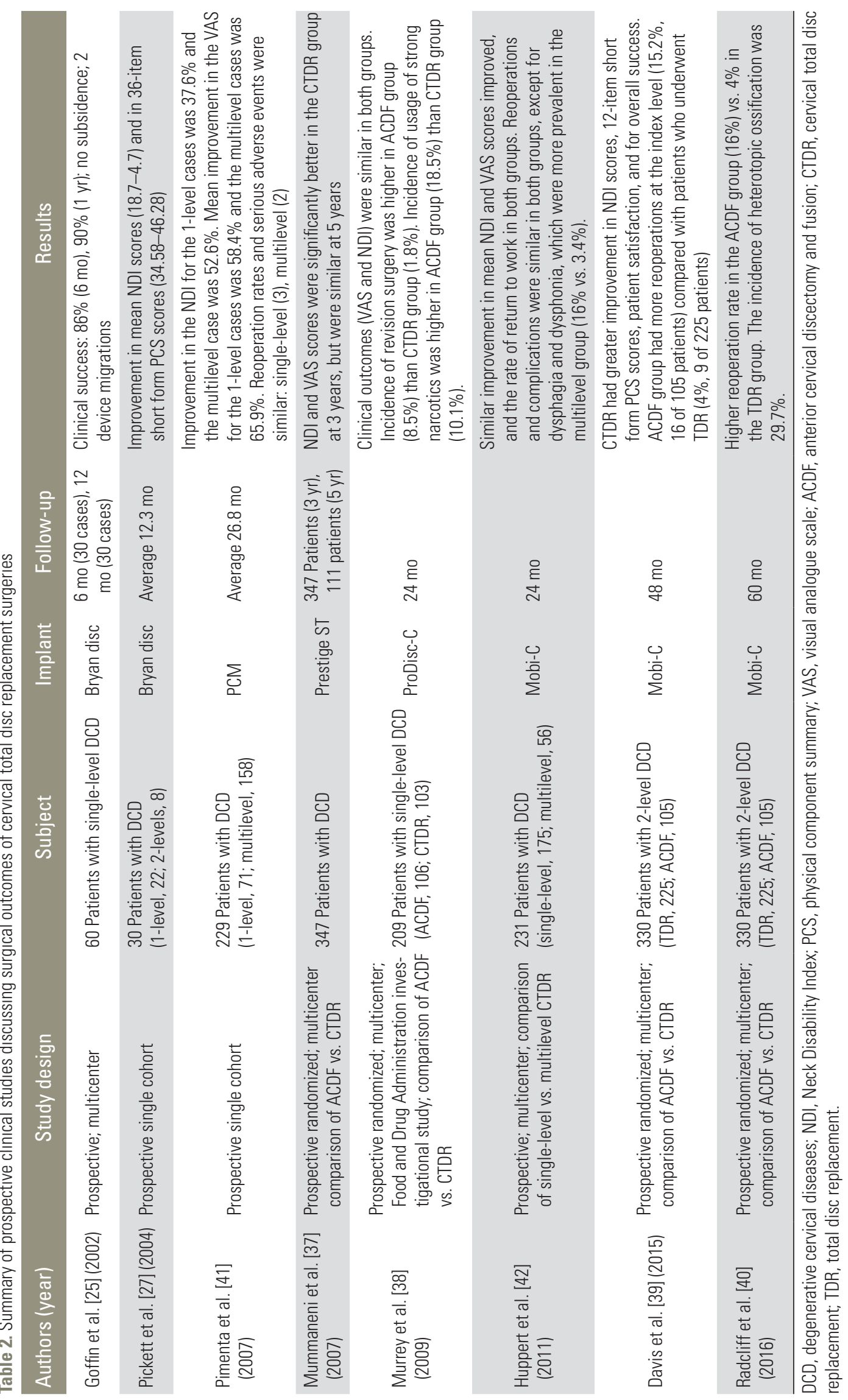


despite a $29.7 \%$ rate of heterotopic ossification (HO).

Recently, Mehren et al. [43] presented the results of a nonrandomized prospective study which determined clinical and radiological outcomes of 50 patients at 10 years of follow-up after CTDR using the ProDisc-C. They observed that significant clinical improvements were maintained at last follow-up (VAS arm, 6.3-2.1; VAS neck, 6.4-1.9; NDI, 2.1-6). The incidence and the extent of $\mathrm{HO}$ were found to be increased with a significant influence on the prosthesis mobility; however, there was no relationship with clinical symptoms. Segmental motion of the index level declined from $9.0^{\circ}$ preoperatively and $9.1^{\circ}$ at 1 year to $7.7^{\circ}$ and $7.6^{\circ}$ at the 5- and 10-year examinations, respectively. Radiological signs of ASD were detected in 13/38 (35.7\%), and 3/38 (7.9\%) patients showing these radiological changes exhibited clinical symptoms requiring conservative treatment. In two cases, intraoperative technical failure required interbody fusion with a cage $(2 / 50)$. One patient $(1 / 48,2.1 \%)$ required revision surgery at the index level.

\section{1) Authors' series}

The authors performed a comparison study between the Bryan disc and the ProDisc-C [44]. After final follow-up visits, mean VAS and NDI scores were found to be significantly lower than their preoperative values; mean VAS score reduced from $7.2 \pm 2.1$ to $1.5 \pm 1.6$, and mean NDI score reduced from $41.8 \% \pm 21.6 \%$ to $9.6 \% \pm 13.2 \%$. The authors' other study focused on degenerative changes of the facet joints and the incidence of $\mathrm{HO}$ after CTDR [45]. At the index level, progression of facet arthrosis (PFA) was observed in 7 of 36 levels (1 level with the Bryan disc, 6 with the ProDisc-C). At adjacent levels, PFA was minimally observed. The HO was observed at 19 levels (11 with the Bryan disc, 8 with ProDisc-C). PFA at the index segments was positively related to prosthesis malposition on the frontal plane, and decreased postoperative functional spinal unit ROM at the index level. Occurrence of the $\mathrm{HO}$ was correlated with preoperative calcification of the PLL at the operative level, regardless of prosthesis type. Clinical outcomes and the occurrence of PFA or $\mathrm{HO}$ were unrelated. According to the authors' experiences, CTDR is a safe and effective treatment modality; however, various undesirable postoperative changes occur in operated and adjacent segments including $\mathrm{HO}$ or PFA following CTDR using both unconstrained and semiconstrained devices. Although these changes were unrelated to clinical outcomes and recent studies have revealed relatively fa- vorable results of CTDR, preventive measures should be taken to avoid these postoperative changes because they may lead to potentially threatening outcomes in a longterm follow-up.

\section{Adjacent segment degeneration}

ACDF is the most frequently used cervical spine surgical procedure. However, increases in the number of fusion surgeries as well as in the duration of follow-up have raised serious concerns about ASD. Since early 2000s, motion preservation technology has been used in clinical practice; ever since, ASD has become a popular issue of debate in the community of spine surgeons because this new technology was developed with the expectation of minimizing the effects on ASD. The clinical significance of this expectation is a popular topic of discussion in scientific meetings.

ASD is defined as a newly-developed degeneration at the operative level, or levels adjacent to the operative level in the spine. ASD has two subtypes: one is symptomatic ASD, accompanied with relevant clinical findings such as myelopathy, radiculopathy, or instability; the other is radiographic $\mathrm{ASD}$, representing the radiographic changes and without relevant symptoms. For the symptomatic ASD, the rates of incidence reported by Hilibrand and Robbins [9] are frequently cited and generally accepted. They indicate that approximately $3 \%$ cases per year were asymptomatic and $25.6 \%$ were asymptomatic at 10 years after ACDF. Recently Xia et al. [46] reported that the occurrence of radiographic ASD was 32.8\% and that of symptomatic ASD was $6.3 \%$ in their systematic review and meta-analysis of 94 published studies involving 34,716 patients with follow-ups that ranged from fewer than half a year to more than 20 years. According to these clinical observations, the discrepancy in incidence between radiographic and symptomatic ASDs is an indisputable fact. However, it is still unknown if radiographic degeneration can be a precursor for symptomatic spondylosis [47]. The etiology of ASD is multifactorial and depends on (1) the natural history of the adjacent disc, (2) biomechanical stress on the adjacent level caused by the fusion, and (3) anatomical disruption at the adjacent level during the initial surgery [48-50]. The identity of the major factor contributing to the development of ASD remains undetermined, although biomechanical and clinical studies suggest that ACDF influences may accelerate the natural 
degenerative processes $[8,51,52]$.

TDR may reduce the incidence of ASD. However, the association of CTDR is still a subject of debate [8,53]. Recently, Nunley et al. [54] presented an annual incidence of symptomatic ASD of $3.1 \%$ after CTDR in 173 patients using data of four different prospective randomized trials with a median follow-up of 51 months. Kelly et al. [55] compared 100 CTDR and 99 ACDF cases from the radiographical IDE studies at the 2-year follow-up point and observed no statistical difference in ROM at adjacent levels between the two groups. Maldonado et al. [56] assessed radiological ASD in CTDR and ACDF groups after 36 months follow-up; 8.8\% patients presented with ASD after CTDR; $10.5 \%$ patients presented with ASD after ACDF. This difference was not statistically significant. Meanwhile, Coric et al. [57] published the results of the IDE trial, where improved radiological outcomes were observed in patients with CTDR versus those with ACDF. Another report of the IDE trial studying the superior outcomes and inferior occurrence rate of radiographic ASD in patients with CTDR to those in patients with ACDF at two contiguous cervical degenerative lesions has been published [39]. Very recently, Zhu et al. [58] reported the results of meta-analysis of 14 randomized controlled trials. Here they evaluated the reported rate of symptomatic ASD in patients with CTDR compared with that in patients with ACDF. They found that CTDR was superior to ACDF, exhibits less ASD and requires few reoperations; they determined that CTDR was a better surgical procedure for reducing the incidence of ASD. In biomechanical models, CTDR was found to be better than ACDF in mimicking the native cervical ROM at adjacent levels [59-62]. No studies have reported evidence of the effects of ACDF on the occurrence of symptomatic ASD in the spine [63]. Nowadays, CTDR might be more recognized as an alternative treatment modality to ACDF than before, because many favorable results in preventive effects of CTDR have been published as mentioned above. However, Helgeson et al. [8] argued in their review article on ASD that, although recent studies provide a high level of evidence, conclusions about the effects of motion preservation on ASD cannot be drawn because of the necessity for long-term follow-up.

\section{Heterotopic ossification}

Many investigators have reported the occurrence of $\mathrm{HO}$

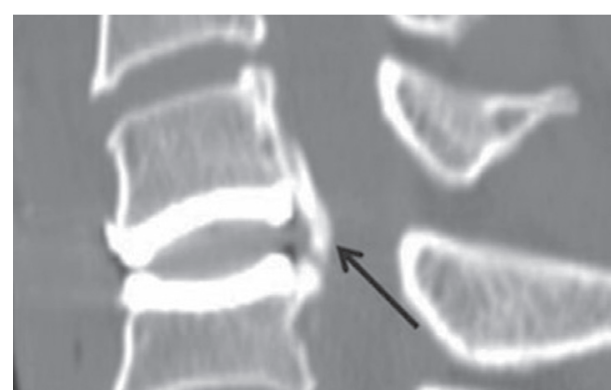

Fig. 4. Sagittal computed tomography scan shows heterotopic ossification at the same level after 26 months of arthroplasty using a Bryan disc placement. The abnormal ossification behind the implant indicates it is McAfee Class II (arrow).

in the follow-up studies of the patients who underwent CTDR (Fig. 4). HO is a well-known and unexplained phenomenon after large joint replacement surgery and has become an unexplained phenomenon following CTDR. $\mathrm{HO}$ appears to have a wide range of incidence. In the authors' series, a high incidence rate of 53\% was observed during a 25-month follow-up cohort study of CTDR [45]. Such high incidence rates of $\mathrm{HO}$ can also be found in both the short- and long-term follow-up periods of other studies; $40.6 \%$ incidence rate in 170 patients in an average of 19.9 months of follow-up [64] and 37\% incidence rate in 24 consecutive patients in an average of 7.7 years of follow-up [65]. In the meantime, some reports revealed relatively lower incidence rate; $2.9 \%$ in 2-year of follow-up [38] and 5.8\% of 103 patients in 5-year of follow-up [66].

Recently, several articles dealing with pathogenesis of HO have emerged. The authors have reported that HO could be caused by iatrogenic factors as a normal defense mechanism against the non-physiological motion of artificial discs and biomechanical stress related to motion of artificial discs. HO may also result from constitutional factors such as preoperative calcification, osteophytes, or ossification of the surrounding structures [67]. Recently published articles studying the mechanism of $\mathrm{HO}$ formation following CTDR tended to focus on the postoperative biomechanical influence of the artificial disc on HO. Kim and Heo [68] presented postoperative biomechanical changes, such as overcorrection of disc space height by use of a CTDR level that is too high, could influence the severity of HO. Tian et al. [69] also reported that HO did not occur in the soft tissue (like typical HO) but rather occurred in the bony vertebral body (96.2\% of HO). Based on this result, they insisted that the ossification associated with CTDR should be called 'paravertebral ossification' rather 
than HO. HO might result from postoperative development of preoperatively existing osteophytes and improper motion of the artificial disc. Jin et al. [70] proposed a new classification for $\mathrm{HO}$, in which $\mathrm{HO}$ was divided into three types (endplate, tear-drop, and traction spur types) according to the morphologic features of $\mathrm{HO}$ formed by relevant biomechanical influence. These three articles appear to have observed $\mathrm{HO}$ from different points of view, but with a common viewpoint, specifically, the importance of postoperative biomechanical factors in the formation of $\mathrm{HO}$ after CTDR. Considering these biomechanical factors, we can emphasize the importance of selecting a biomechanicallyrelevant motion device to avoid $\mathrm{HO}$ formation.

Nowadays, there exist various suggested countermeasures for avoiding HO formation. These include selecting proper candidates, gentle handling of soft tissues, strict hemostasis (particularly, using bone wax during surgery), avoiding too much dissection of the longus coli, washing the operation field thoroughly, and administering nonsteroidal anti-inflammatory drugs (NSAIDs). Considering biomechanical factors in the formation of $\mathrm{HO}$, more physiological devices can be added as new countermeasures. Among these countermeasures, selecting proper candidates is important. Proper candidates are the patients who have preoperative soft cervical disc herniation only but no ossified PLL, bony spurs, collapsed disc space or instability. The prophylactic use of NSAIDs clearly decreased the incidence of postoperative $\mathrm{HO}$ in patients with hip arthroplasty [71]. However, whether HO in CTDR can be prevented by postoperative use of NSAIDs is yet to be determined. Tu et al. [72] evaluated the efficacy of NSAIDs in preventing $\mathrm{HO}$ following CTDR. They concluded that less $\mathrm{HO}$ formation was observed in patients who used postoperative NSAIDs following CTDR than those who did not, but this difference was not statistically significant. In the authors' series, even if we routinely gave postoperative NSAIDs to all registered cases until postoperative day 7 , the occurrence rate of $\mathrm{HO}$ was still higher than those reported in other HO studies without NSAID usage [45]. Considering the issue of bleeding, and the cardiovascular or gastrointestinal complications of NSAIDs and low clinical significance of $\mathrm{HO}$ altogether, routine use of prophylactic NSAIDS for HO after CTDR cannot be justified [73]. Further studies are required to assess the role of NSAIDs in the development of $\mathrm{HO}$ following CTDR [74].

Although HO induced artificial discs to lose the most important function of motion preservation at the end, no difference was observed in clinical outcomes of the patients with $\mathrm{HO}$ compared with those without $\mathrm{HO}$ in 5-year follow-up in a US FDA IDE study with ProDisc-C [66]. Zhou et al. [75] conducted a meta-analysis of nine cohort studies with more than 2 years of follow-up and reported that the presence of $\mathrm{HO}$ was not associated with clinical outcomes after CTDR. If a patient with a wellfused index segment following ACDF has relatively good outcomes, loss of segmental motion by HO may not have a significant negative impact. HO-related effects on longterm outcomes have not been verified. Trials with even longer follow-up periods are required to understand the definite prognostic value of $\mathrm{HO}$.

\section{Wear debris and tissue reaction}

Globally, there are numerous varieties of implants for CTDR, and there are various ways to classify these prostheses. Considering the materials used for the bearing surface, CTDRs in the market could be largely divided into two kinds: metal-on-metal (MoM) and metal-onpolyethylene (MoP).

Concerns about metallic wear follow use of MoM TDR. One example is Maverick, which was withdrawn from the US market. Some investigators have cited a threshold serum ion level for predicting complications with MoM prostheses, with below-threshold serum ion levels associated with increased safety [76]. However, the correlation (if any) between serum ion levels and clinical problems remains undetermined. Gornet et al. [77] reported elevated postoperative serum ion levels, even in patients with wellfunctioning MoM TDR in a prospective study of $24 \mathrm{pa}-$ tients. The authors insisted that no reliable threshold values were currently available for circulating serum metallic debris following arthroplasty surgery. Considering these observations, clinical implications of local tissue and systemic ionic concentrations remain uncertain. Therefore, even when serum ion levels are lower than the threshold, a patient with MoM TDR cannot be free from the potential risk of hypersensitivity and other biologic responses. Importantly, released ionic compounds can trigger an immune reaction anytime, potentially producing osteolysis and prosthesis failure $[78,79]$ as consequences of cell-mediated hypersensitivity, which has been well documented for hip and knee arthroplasty.

Until recently, PE wear was not a clinically relevant issue for spine TDR as there is no synovial joint in the 
intervertebral disc and the limitation of motion between the lower lumbar segments. These days, it is well known that PE particles may induce osteolysis and aseptic loosening. Punt et al. [80] reported that they could observe $\mathrm{PE}$ and chronic inflammatory reactions in periprosthetic tissue collected during reoperation in 15 of 16 patients with MoP. Among the 15 who underwent reoperation, two patients had received prosthesis only 3 years prior, and the investigators observed $\mathrm{PE}$ and macrophages in their collected peri-prosthetic tissues. Kurtz et al. [81] reported the results of quantitatively analyzing long-term mechanisms of PE damage in contemporary TDRs stating that increasing wear with implantation time might be accompanied with a potential risk for osteolysis in the spine during long-term follow-up. Recently, the use of highly cross-linked PE has reduced the wear rate. This evolution came from an increased understanding of PE over the last 20 years [82]. MoP using cobalt-chromium-molybdenum and modern ultrahigh molecular weight polyethylene (UHMWPE) is regarded as a reference standard based on its extensive clinical use as a bearing surface. However, development of new materials engineering may not fully protect TDR from wear-related issues. A debris-induced tissue reaction that caused peri-prosthetic osteolysis in a patient with UHMWPE TDR has been reported [83].

Most of the patients who receive TDR are relatively young and have active life styles. Consequently, wear and local tissue responses may emerge as major issues in these patients at long-term follow-up [84]. Small number of wear-related complications have been reported which represent an overall low rate of wear-related complications. Nevertheless, we cannot know if this overall low rate of wear-related issues will continue as time passes. Prosthesis wear is usually accompanied with a poor biomechanical status such as subsidence, migration, and undersizing. Here, wear could adversely affect outcomes. In such patients, unknown complications can occur which spine surgeons have never experienced in fusion surgery. Regular long-term follow-up and spine surgeons' awareness of these potential complications are strongly warranted.

\section{Multilevel TDR and hybrid surgery in multilevel cer- vical disc diseases}

In multilevel cervical disc diseases, ACDF is the most widely accepted surgical procedure with a satisfactory pain and functional outcome and significantly high radio- logical fusion. However, clinical outcomes and radiological fusion rates deteriorate as the number of involved disc levels increases because longer fusions may cause greater stresses at adjacent levels than a single-level fusion $[85,86]$. Unlike ACDF, TDR has benefits such as preservation of both spinal mobility and stability $[41,87]$, reduction of symptomatic ASD, and avoidance of fusion-related complications. Therefore, TDR appears to be a more effective procedure than ACDF for multilevel surgery if both have the same effects on neurological decompression. Because 2-level TDR was recently approved in the United States, little data is available for comparison between 2-level TDR and 2-level ACDF.

A recent post-hoc comparison clinical study with a 4-year follow-up between 1-level Mobi-C cervical artificial disc and 2-level TDR was published [88]. The patients, 179 with 1-level and 234 with 2-level, were concurrently enrolled in a multicenter US FDA IDE clinical trial. The authors found no difference between 1-level and 2-level TDR in all outcome measures, overall complications, and subsequent surgery rates. The authors concluded that their clinical trial demonstrated that 2-level TDR is as safe and effective as 1-level TDR for a few patients. Approximately 1 year before the publishing of this report, Davis et al. [39] reported their 4-year follow-up results on the same cohort of patients who underwent 2-level TDR as shown in the previous report, but with a smaller number of TDR patients. This comparison study between TDR and ACDF was conducted in 225 patients with TDR and 105 patients with ACDF at 24 centers in the United States. Patients with TDR, especially those undergoing treatment of two contiguous cervical levels, demonstrated significantly greater improvement than patients with $\mathrm{ACDF}$ for most of the outcome measures, including overall success compared to baseline. ACDF patients exhibited a higher rate of radiographic ASD. Previously, this group had reported 2-year follow-up results from the same patient cohort. They found that 2-level TDR produced statistically better outcomes for both pain and function [89]. Continuation of long-term follow-ups of this patient cohort should establish 2-level TDR as a superior alternative to ACDF. Very recently, Joaquim and Riew [90] performed a systematic review of the clinical studies evaluating patients who underwent multilevel CTDR ( 2 or more levels). In their systematic review of 14 clinical studies, most of the literature supports use of CTDR in multilevel cervical disc degeneration. The authors proposed further prospec- 
tive, controlled, multicenter, and randomized studies to elucidate the superiority of CTDR over ACDF for treating cervical disc degeneration in selected cases.

As mentioned above, in surgical treatments of multilevel cervical degenerative diseases, multilevel fusion has a greater chance of causing ASD than single-level fusion. Hybrid surgery (HS), where ACDF and TDR are incorporated at different levels, can be a beneficial surgical treatment for multilevel cervical degenerative lesions to avoid the harmful effects of long-level fusions such as exacerbating ASD by combining the advantages of both ACDF and TDR techniques. However, not all the levels with cervical disease may be acceptable for TDR. In multilevel cervical degenerative diseases, there are often lesions that are acceptable and unacceptable for TDR. Surgeons can combine these techniques, using TDR at levels where it is effective and ACDF at levels that favor bony fusion. The major advantage of HS is that the technique allows for maintaining motion in multilevel diseases, which were previously fused and immobilized in long segments. HS should be performed in carefully selected patients and its feasibility as an alternative to TDR and ACDF for managing multilevel cervical degenerative disc diseases requires further elucidation.

Hey et al. [91] reported the results of a direct comparison study of three groups (ACDF, TDR, and HS) in multilevel cervical degenerative diseases with a minimum 2-year follow-up and concluded that HS could be a feasible and safe alternative to multilevel TDR or multilevel ACDF. In many aspects, the results of HS were a balance between TDR and ACDF. Alvin and Mroz [92] reported similar results in a comparison study of TDR and ACDF in 2-level cervical degenerative disc diseases in which they concluded that TDR group may be superior to ACDF group. Lee e al. [93] reported the results of 2- to 3-level HS in multilevel cervical spondylosis with 2-year followup, and demonstrated that HS is a safe and effective alternative to ACDF.

When compiling all data to date, multilevel cervical TDR and HS appear to be safe and effective alternatives to ACDF in selected patients. Considering the various pathologies concurrently observed in a single patient with degenerative cervical disease, TDR should be applied only in selected levels of multilevel-lesions. TDR should not be used in discs with ossification of posterior longitudinal ligament, discs with advanced degenerative disease, facetopathy, stenosis, or instability. Thus, a surgeon may have more chances to choose HS in patients with multilevel degenerative cervical disease. Multilevel TDR and HS in the cervical spine are associated with favorable outcome measures, ASD, complications, and second surgery rates. However, these surgical treatment modalities still require additional clinical data and long-term follow-ups.

\section{Conclusion}

CTDR is a new and innovative technology with limited indications for clinical application in spinal surgery. Most studies dealing with CTDR and its outcomes have reported favorable results in various outcome measures. However, some controversial issues such as outcomes, ASD, HO, wear debris, multilevel TDR, and HS remain unresolved. Based on the study results reported in the literature so far, favorable evidence related to outcomes, ASD, multilevel TDR, and HS exist. However, these issues still remain debatable. It will take considerable time to provide proper answers for these issues. We need to wait and examine results obtained from long-term follow-ups prior to forming conclusions about these controversial issues and the clinical relevance of CTDR.

\section{Conflict of Interest}

No potential conflict of interest relevant to this article was reported.

\section{Acknowledgments}

The author is thankful to Miss So Ha Park for her sincere editorial assistance.

\section{References}

1. Van Eck CF, Regan C, Donaldson WF, Kang JD, Lee JY. The revision rate and occurrence of adjacent segment disease after anterior cervical discectomy and fusion: a study of 672 consecutive patients. Spine (Phila Pa 1976) 2014;39:2143-7.

2. Ahn SS, So WS, Ku MG, Kim SH, Kim DW, Lee BH. Radiologic findings and risk factors of adjacent segment degeneration after anterior cervical discectomy and fusion: a retrospective matched cohort study with 3-year follow-up using MRI. J Korean Neurosurg Soc 2016;59:129-36. 
3. Elsawaf A, Mastronardi L, Roperto R, Bozzao A, Caroli M, Ferrante L. Effect of cervical dynamics on adjacent segment degeneration after anterior cervical fusion with cages. Neurosurg Rev 2009;32:215-24.

4. Guan T, Hu Z, Xiu L, Li N, Jin Q. Effect of cervical disc arthroplasty and anterior cervical decompression and fusion on adjacent segment degeneration. Zhongguo Xiu Fu Chong Jian Wai Ke Za Zhi 2014;28:1100-5.

5. Lundine KM, Davis G, Rogers M, Staples M, Quan G. Prevalence of adjacent segment disc degeneration in patients undergoing anterior cervical discectomy and fusion based on pre-operative MRI findings. J Clin Neurosci 2014;21:82-5.

6. Matsumoto M, Okada E, Ichihara D, et al. Anterior cervical decompression and fusion accelerates adjacent segment degeneration: comparison with asymptomatic volunteers in a ten-year magnetic resonance imaging follow-up study. Spine (Phila Pa 1976) 2010;35:36-43.

7. Park JY, Kim KH, Kuh SU, Chin DK, Kim KS, Cho YE. What are the associative factors of adjacent segment degeneration after anterior cervical spine surgery?: comparative study between anterior cervical fusion and arthroplasty with 5-year follow-up MRI and CT. Eur Spine J 2013;22:1078-89.

8. Helgeson MD, Bevevino AJ, Hilibrand AS. Update on the evidence for adjacent segment degeneration and disease. Spine J 2013;13:342-51.

9. Hilibrand AS, Robbins M. Adjacent segment degeneration and adjacent segment disease: the consequences of spinal fusion? Spine J 2004;4(6 Suppl):190S-194S.

10. Gornet MF, Lanman TH, Burkus JK, et al. Cervical disc arthroplasty with the Prestige LP disc versus anterior cervical discectomy and fusion, at 2 levels: results of a prospective, multicenter randomized controlled clinical trial at 24 months. J Neurosurg Spine 2017;26:653-67.

11. Obernauer J, Landscheidt J, Hartmann S, Schubert GA, Thome C, Lumenta C. Cervical arthroplasty with ROTAIO cervical disc prosthesis: first clinical and radiographic outcome analysis in a multicenter prospective trial. BMC Musculoskelet Disord 2016;17:11.

12. Phillips FM, Geisler FH, Gilder KM, Reah C, Howell KM, McAfee PC. Long-term outcomes of the US
FDA IDE Prospective, Randomized Controlled Clinical Trial comparing PCM cervical disc arthroplasty with anterior cervical discectomy and fusion. Spine (Phila Pa 1976) 2015;40:674-83.

13. Phillips FM, Lee JY, Geisler FH, et al. A prospective, randomized, controlled clinical investigation comparing PCM cervical disc arthroplasty with anterior cervical discectomy and fusion. 2-year results from the US FDA IDE clinical trial. Spine (Phila Pa 1976) 2013;38:E907-18.

14. Sasso RC, Anderson PA, Riew KD, Heller JG. Results of cervical arthroplasty compared with anterior discectomy and fusion: four-year clinical outcomes in a prospective, randomized controlled trial. J Bone Joint Surg Am 2011;93:1684-92.

15. Sasso RC, Smucker JD, Hacker RJ, Heller JG. Clinical outcomes of BRYAN cervical disc arthroplasty: a prospective, randomized, controlled, multicenter trial with 24-month follow-up. J Spinal Disord Tech 2007;20:481-91.

16. Sasso WR, Smucker JD, Sasso MP, Sasso RC. Longterm clinical outcomes of cervical disc arthroplasty: a prospective, randomized, controlled trial. Spine (Phila Pa 1976) 2016 Jun 21 [Epub]. https://doi. org/10.1097/BRS.0000000000001746.

17. Sasso WR, Smucker JD, Sasso MP, Sasso RC. Longterm clinical outcomes of cervical disc arthroplasty: a prospective, randomized, controlled trial. Spine (Phila Pa 1976) 2017;42:209-16.

18. Sundseth J, Fredriksli OA, Kolstad F, et al. The Norwegian Cervical Arthroplasty Trial (NORCAT): 2-year clinical outcome after single-level cervical arthroplasty versus fusion-a prospective, singleblinded, randomized, controlled multicenter study. Eur Spine J 2017;26:1225-35.

19. Buttner-Janz K. Optimal minimally traumatic approach for the SB Charite Artificial Disc. Eur Spine J 2002;11 Suppl 2:S111-4.

20. Cinotti G, David T, Postacchini F. Results of disc prosthesis after a minimum follow-up period of 2 years. Spine (Phila Pa 1976) 1996;21:995-1000.

21. David T. Long-term results of one-level lumbar arthroplasty: minimum 10-year follow-up of the CHARITE artificial disc in 106 patients. Spine (Phila Pa 1976) 2007;32:661-6.

22. Griffith SL, Shelokov AP, Buttner-Janz K, LeMaire JP, Zeegers WS. A multicenter retrospective study of the 
clinical results of the LINK SB Charité intervertebral prosthesis: the initial European experience. Spine (Phila Pa 1976) 1994;19:1842-9.

23. Szpalski M, Gunzburg R, Mayer M. Spine arthroplasty: a historical review. Eur Spine J 2002;11 Suppl 2:S65-84.

24. Wigfield CC, Gill SS, Nelson RJ, Metcalf NH, Robertson JT. The new Frenchay artificial cervical joint: results from a two-year pilot study. Spine (Phila Pa 1976) 2002;27:2446-52.

25. Goffin J, Casey A, Kehr P, Liebig K, Lind B, Logroscino C, Pointillart V, Van Calenbergh F, van Loon J. Preliminary clinical experience with the Bryan cervical disc prosthesis. Neurosurgery 2002;51:840-5.

26. Yoon DH, Yi S, Shin HC, Kim KN, Kim SH. Clinical and radiological results following cervical arthroplasty. Acta Neurochir (Wien) 2006;148:943-50.

27. Pickett GE, Mitsis DK, Sekhon LH, Sears WR, Duggal N. Effects of a cervical disc prosthesis on segmental and cervical spine alignment. Neurosurg Focus 2004;17:E5.

28. Fong SY, DuPlessis SJ, Casha S, Hurlbert RJ. Design limitations of Bryan disc arthroplasty. Spine J 2006;6:233-41.

29. Johnson JP, Lauryssen C, Cambron HO, et al. Sagittal alignment and the Bryan cervical artificial disc. Neurosurg Focus 2004;17:E14.

30. Goffin J, van Calenbergh F, van Loon J, et al. Intermediate follow-up after treatment of degenerative disc disease with the Bryan cervical disc prosthesis: single-level and bi-level. Spine (Phila Pa 1976) 2003;28:2673-8.

31. Pickett GE, Sekhon LH, Sears WR, Duggal N. Complications with cervical arthroplasty. J Neurosurg Spine 2006;4:98-105.

32. Murrey DB, Janssen ME, Odum SM, Gottlieb JR, Spector LR, Darden BV. Two-year results of a randomized controlled clinical trial comparing ProDisc$\mathrm{C}$ and anterior cervical discectomy and fusion. SAS J 2008;2:76-85.

33. Jaramillo-de la Torre JJ, Grauer JN, Yue JJ. Update on cervical disc arthroplasty: where are we and where are we going? Curr Rev Musculoskelet Med 2008;1:124-30.

34. Kim SW, Paik SH, Castro PA, et al. Analysis of factors that may influence range of motion after cervical disc arthroplasty. Spine J 2010;10:683-8.
35. Snyder JT, Tzermiadianos MN, Ghanayem AJ, et al. Effect of uncovertebral joint excision on the motion response of the cervical spine after total disc replacement. Spine (Phila Pa 1976) 2007;32:2965-9.

36. Bono CM, Ghiselli G, Gilbert TJ, et al. An evidencebased clinical guideline for the diagnosis and treatment of cervical radiculopathy from degenerative disorders. Spine J 2011;11:64-72.

37. Mummaneni PV, Burkus JK, Haid RW, Traynelis VC, Zdeblick TA. Clinical and radiographic analysis of cervical disc arthroplasty compared with allograft fusion: a randomized controlled clinical trial. J Neurosurg Spine 2007;6:198-209.

38. Murrey D, Janssen M, Delamarter R, et al. Results of the prospective, randomized, controlled multicenter Food and Drug Administration investigational device exemption study of the ProDisc-C total disc replacement versus anterior discectomy and fusion for the treatment of 1-level symptomatic cervical disc disease. Spine J 2009;9:275-86.

39. Davis RJ, Nunley PD, Kim KD, et al. Two-level total disc replacement with Mobi-C cervical artificial disc versus anterior discectomy and fusion: a prospective, randomized, controlled multicenter clinical trial with 4-year follow-up results. J Neurosurg Spine 2015;22:15-25.

40. Radcliff K, Coric D, Albert T. Five-year clinical results of cervical total disc replacement compared with anterior discectomy and fusion for treatment of 2-level symptomatic degenerative disc disease: a prospective, randomized, controlled, multicenter investigational device exemption clinical trial. J Neurosurg Spine 2016;25:213-24.

41. Pimenta L, McAfee PC, Cappuccino A, Cunningham BW, Diaz R, Coutinho E. Superiority of multilevel cervical arthroplasty outcomes versus single-level outcomes: 229 consecutive PCM prostheses. Spine (Phila Pa 1976) 2007;32:1337-44.

42. Huppert J, Beaurain J, Steib JP, et al. Comparison between single- and multi-level patients: clinical and radiological outcomes 2 years after cervical disc replacement. Eur Spine J 2011;20:1417-26.

43. Mehren C, Heider F, Siepe CJ, et al. Clinical and radiological outcome at 10 years of follow-up after total cervical disc replacement. Eur Spine J 2017 Jul 4 [Epub]. https://doi.org/10.1007/s00586-017-5204-6.

44. Ryu KS, Heo HY, Lee SJ, Lee KY, Park CK. Prognostic 
factors related to motion dynamics following cervical arthroplasty with a bryan disc: average 2-year followup. SAS J 2008;2:86-91.

45. Ryu KS, Park CK, Jun SC, Huh HY. Radiological changes of the operated and adjacent segments following cervical arthroplasty after a minimum 24-month follow-up: comparison between the Bryan and Prodisc-C devices. J Neurosurg Spine 2010;13:299-307.

46. Xia XP, Chen HL, Cheng HB. Prevalence of adjacent segment degeneration after spine surgery: a systematic review and meta-analysis. Spine (Phila Pa 1976) 2013;38:597-608.

47. Ueda H, Huang RC, Lebl DR. Iatrogenic contributions to cervical adjacent segment pathology: review article. HSS J 2015;11:26-30.

48. Weinhoffer SL, Guyer RD, Herbert M, Griffith SL. Intradiscal pressure measurements above an instrumented fusion: a cadaveric study. Spine (Phila Pa 1976) $1995 ; 20: 526-31$.

49. Park P, Garton HJ, Gala VC, Hoff JT, McGillicuddy JE. Adjacent segment disease after lumbar or lumbosacral fusion: review of the literature. Spine (Phila Pa 1976) 2004;29:1938-44.

50. Rahm MD, Hall BB. Adjacent-segment degeneration after lumbar fusion with instrumentation: a retrospective study. J Spinal Disord 1996;9:392-400.

51. Lee MJ, Dettori JR, Standaert CJ, Brodt ED, Chapman JR. The natural history of degeneration of the lumbar and cervical spines: a systematic review. Spine (Phila Pa 1976) 2012;37(22 Suppl):S18-30.

52. Yue WM, Brodner W, Highland TR. Long-term results after anterior cervical discectomy and fusion with allograft and plating: a 5- to 11-year radiologic and clinical follow-up study. Spine (Phila Pa 1976) 2005;30:2138-44.

53. Saavedra-Pozo FM, Deusdara RA, Benzel EC. Adjacent segment disease perspective and review of the literature. Ochsner J 2014;14:78-83.

54. Nunley PD, Jawahar A, Cavanaugh DA, Gordon CR, Kerr EJ 3rd, Utter PA. Symptomatic adjacent segment disease after cervical total disc replacement: reexamining the clinical and radiological evidence with established criteria. Spine J 2013;13:5-12.

55. Kelly MP, Mok JM, Frisch RF, Tay BK. Adjacent segment motion after anterior cervical discectomy and fusion versus Prodisc-c cervical total disk arthro- plasty: analysis from a randomized, controlled trial. Spine (Phila Pa 1976) 2011;36:1171-9.

56. Maldonado CV, Paz RD, Martin CB. Adjacent-level degeneration after cervical disc arthroplasty versus fusion. Eur Spine J 2011;20 Suppl 3:403-7.

57. Coric D, Nunley PD, Guyer RD, et al. Prospective, randomized, multicenter study of cervical arthroplasty: 269 patients from the Kineflex|C artificial disc investigational device exemption study with a minimum 2-year follow-up: clinical article. J Neurosurg Spine 2011;15:348-58.

58. Zhu Y, Zhang B, Liu H, Wu Y, Zhu Q. Cervical disc arthroplasty versus anterior cervical discectomy and fusion for incidence of symptomatic adjacent segment disease: a meta-analysis of prospective randomized controlled trials. Spine (Phila Pa 1976) 2016;41:1493-502.

59. DiAngelo DJ, Roberston JT, Metcalf NH, McVay BJ, Davis RC. Biomechanical testing of an artificial cervical joint and an anterior cervical plate. J Spinal Disord Tech 2003;16:314-23.

60. Wigfield C, Gill S, Nelson R, Langdon I, Metcalf N, Robertson J. Influence of an artificial cervical joint compared with fusion on adjacent-level motion in the treatment of degenerative cervical disc disease. J Neurosurg 2002;96(1 Suppl):17-21.

61. Cunningham BW, Hu N, Zorn CM, McAfee PC. Biomechanical comparison of single- and two-level cervical arthroplasty versus arthrodesis: effect on adjacent-level spinal kinematics. Spine J 2010;10:3419.

62. Auerbach JD, Anakwenze OA, Milby AH, Lonner BS, Balderston RA. Segmental contribution toward total cervical range of motion: a comparison of cervical disc arthroplasty and fusion. Spine (Phila Pa 1976) 2011;36:E1593-9.

63. Verma K, Gandhi SD, Maltenfort M, et al. Rate of adjacent segment disease in cervical disc arthroplasty versus single-level fusion: meta-analysis of prospective studies. Spine (Phila Pa 1976) 2013;38:2253-7.

64. Yi S, Shin DA, Kim KN, et al. The predisposing factors for the heterotopic ossification after cervical artificial disc replacement. Spine J 2013;13:1048-54.

65. Malham GM, Parker RM, Ellis NJ, Chan PG, Varma D. Cervical artificial disc replacement with ProDiscC: clinical and radiographic outcomes with longterm follow-up. J Clin Neurosci 2014;21:949-53. 
66. Zigler JE, Delamarter R, Murrey D, Spivak J, Janssen M. ProDisc-C and anterior cervical discectomy and fusion as surgical treatment for single-level cervical symptomatic degenerative disc disease: five-year results of a Food and Drug Administration study. Spine (Phila Pa 1976) 2013;38:203-9.

67. Cho HJ, Shin MH, Huh JW, Ryu KS, Park CK. Heterotopic ossification following cervical total disc replacement: iatrogenic or constitutional? Korean J Spine 2012;9:209-14.

68. Kim KS, Heo DH. Do Postoperative biomechanical changes induce heterotopic ossification after cervical arthroplasty?: a 5-year follow-up study. Clin Spine Surg 2016;29:E309-13.

69. Tian W, Han X, Liu B, He D, Lv Y, Yue J. Generation and development of paravertebral ossification in cervical artificial disk replacement: a detailed analytic report using coronal reconstruction CT. Clin Spine Surg 2017;30:E179-E88.

70. Jin YJ, Park SB, Kim MJ, Kim KJ, Kim HJ. An analysis of heterotopic ossification in cervical disc arthroplasty: a novel morphologic classification of an ossified mass. Spine J 2013;13:408-20.

71. Yeung M, Jamshidi S, Horner N, Simunovic N, Karlsson J, Ayeni OR. Efficacy of nonsteroidal antiinflammatory drug prophylaxis for heterotrophic ossification in hip arthroscopy: a systematic review. Arthroscopy 2016;32:519-25.

72. Tu TH, Wu JC, Huang WC, et al. Postoperative nonsteroidal antiinflammatory drugs and the prevention of heterotopic ossification after cervical arthroplasty: analysis using CT and a minimum 2-year follow-up. J Neurosurg Spine 2015;22:447-53.

73. Miller GK. Editorial commentary: the efficacy of nonsteroidal anti-inflammatory drugs for prophylaxis of heterotopic ossification in hip arthroscopy: do we treat patients or X-rays? Arthroscopy 2016;32:526-7.

74. Sundseth J, Jacobsen EA, Kolstad F, et al. Heterotopic ossification and clinical outcome in nonconstrained cervical arthroplasty 2 years after surgery: the Norwegian Cervical Arthroplasty Trial (NORCAT). Eur Spine J 2016;25:2271-8.

75. Zhou HH, Qu Y, Dong RP, Kang MY, Zhao JW. Does heterotopic ossification affect the outcomes of cervical total disc replacement?: a meta-analysis. Spine (Phila Pa 1976) 2015;40:E332-40.

76. Van Der Straeten C, Grammatopoulos G, Gill HS,
Calistri A, Campbell P, De Smet KA. The 2012 Otto Aufranc Award: the interpretation of metal ion levels in unilateral and bilateral hip resurfacing. Clin Orthop Relat Res 2013;471:377-85.

77. Gornet MF, Burkus JK, Harper ML, Chan FW, Skipor AK, Jacobs JJ. Prospective study on serum metal levels in patients with metal-on-metal lumbar disc arthroplasty. Eur Spine J 2013;22:741-6.

78. Agarwal S. Osteolysis: basic science, incidence and diagnosis. Curr Orthop 2004;18:220-31.

79. Zeh A, Planert M, Siegert G, Lattke P, Held A, Hein W. Release of cobalt and chromium ions into the serum following implantation of the metal-on-metal Maverick-type artificial lumbar disc (Medtronic Sofamor Danek). Spine (Phila Pa 1976) 2007;32:34852.

80. Punt IM, Cleutjens JP, de Bruin T, et al. Periprosthetic tissue reactions observed at revision of total intervertebral disc arthroplasty. Biomaterials 2009;30:2079-84.

81. Kurtz SM, van Ooij A, Ross R, et al. Polyethylene wear and rim fracture in total disc arthroplasty. Spine J 2007;7:12-21.

82. Jacobs JJ, An HS. Commentary: total disc arthroplasty and the bearing surface debate. Spine J 2012;12:702-4.

83. Harris WH. Wear and periprosthetic osteolysis: the problem. Clin Orthop Relat Res 2001;(393):66-70.

84. Hedman TP, Kostuik JP, Fernie GR, Hellier WG. Design of an intervertebral disc prosthesis. Spine (Phila Pa 1976) 1991;16(6 Suppl):S256-60.

85. Jacobs WC, Anderson PG, Limbeek J, Willems PC, Pavlov P. Single or double-level anterior interbody fusion techniques for cervical degenerative disc disease. Cochrane Database Syst Rev 2004;(4):CD004958.

86. Park DH, Ramakrishnan P, Cho TH, et al. Effect of lower two-level anterior cervical fusion on the superior adjacent level. J Neurosurg Spine 2007;7:33640.

87. Phillips FM, Tzermiadianos MN, Voronov LI, et al. Effect of two-level total disc replacement on cervical spine kinematics. Spine (Phila Pa 1976) 2009;34:E794-9.

88. Bae HW, Kim KD, Nunley PD, et al. Comparison of clinical outcomes of 1- and 2-level total disc replacement: four-year results from a prospective, random- 
ized, controlled, multicenter IDE clinical trial. Spine (Phila Pa 1976) 2015;40:759-66.

89. Davis RJ, Kim KD, Hisey MS, et al. Cervical total disc replacement with the Mobi-C cervical artificial disc compared with anterior discectomy and fusion for treatment of 2-level symptomatic degenerative disc disease: a prospective, randomized, controlled multicenter clinical trial: clinical article. J Neurosurg Spine 2013;19:532-45.

90. Joaquim AF, Riew KD. Multilevel cervical arthroplasty: current evidence: a systematic review. Neurosurg Focus 2017;42:E4.
91. Hey HW, Hong CC, Long AS, Hee HT. Is hybrid surgery of the cervical spine a good balance between fusion and arthroplasty?: pilot results from a single surgeon series. Eur Spine J 2013;22:116-22.

92. Alvin MD, Mroz TE. The Mobi-C cervical disc for one-level and two-level cervical disc replacement: a review of the literature. Med Devices (Auckl) 2014;7:397-403.

93. Lee SB, Cho KS, Kim JY, Yoo DS, Lee TG, Huh PW. Hybrid surgery of multilevel cervical degenerative disc disease: review of literature and clinical results. J Korean Neurosurg Soc 2012;52:452-8. 